\title{
Plasma levels of the active form of suPAR are associated with COVID-19 severity
}

\author{
Mingxiang Huang ${ }^{1 \dagger}$, Linlin $\mathrm{Li}^{2+}$, Jianshan Shen ${ }^{1}$, Yao Wang ${ }^{1}$, Rui Wang ${ }^{1}$, Cai Yuan ${ }^{3}$, Mingdong Huang ${ }^{2 *}$ and \\ Longguang Jiang ${ }^{2,4^{*}}$ (D)
}

We read with great interest the recent study by Rovina et al., who found that the elevation of soluble urokinase plasminogen activator receptor (suPAR) plasma levels in coronavirus disease 2019 (COVID-19) patients, and suggested the suPAR can be an early predictor of severe respiratory failure [1]. There are three different suPAR forms (suPAR DI-III, suPAR DI, and suPAR DII-III) in circulation, in which suPAR DI-III is defined as the active form of suPAR by its capability of binding to uPA [2]. In addition, the uPA/uPAR system as a therapeutic target has been proposed to reduce mortality of COVID-19 [3]; therefore, further evaluation of the active form of suPAR plasma levels in different symptom types of COVID-19 patients and asymptomatic carriers could still provide important indications for required early admission and treatment.

In our study, we found that active suPAR levels in all COVID-19 patients were significantly higher than in healthy controls $(5.51 \pm 2.53 \mathrm{ng} / \mathrm{mL}$ vs $1.97 \pm 0.78 \mathrm{ng} / \mathrm{mL}$, $p<0.0001)$ using a ELISA assay modified from our previously reported method [4] where the active suPAR was captured by a uPAR ligand and measured using a polyclonal anti-uPAR antibody. Strikingly, the active suPAR levels in asymptomatic carriers $(8.08 \pm 4.81 \mathrm{ng} / \mathrm{mL})$ are not only significantly higher than those in healthy controls $(p<0.0001)$ but also slightly higher than those in COVID-19 patients ( $p=0.0278)$ (Table 1, Fig. 1a). Even though more data needs to be collected and the background of these patients are not clear, this is a significant research direction to pursue. If asymptomatic carriers could be identified and quarantined in an early stage, it will prevent them from increasing the disease transmission to an uncontrollable manner.

Patients involved three types of symptoms: moderate, severe, and critical in our study (Table 1). Our data show that active suPAR levels increase as the disease worsens (Fig. 1b). Moreover, correlation analyses demonstrated that active suPAR levels are positively correlated with high-sensitivity C-reaction protein (hs-CRP), neutrophil/ leukocyte ratio, and lymphocyte counts (Table 1).

Therefore, taken together with the results from Rovina et al., these results demonstrated that the active suPAR as a COVID-19 prognostic biomarker may assist in the early triage of SARS-CoV-2-infected persons to prevent virus transmission. Further studies are needed to see whether the elevation of suPAR plasma levels in COVID-19 patients is due to the enhanced over-expression of uPAR or due to their increased shedding from the cell surface. original author(s) and the source, provide a link to the Creative Commons licence, and indicate if changes were made. The images or other third party material in this article are included in the article's Creative Commons licence, unless indicated otherwise in a credit line to the material. If material is not included in the article's Creative Commons licence and your intended use is not permitted by statutory regulation or exceeds the permitted use, you will need to obtain permission directly from the copyright holder. To view a copy of this licence, visit http://creativecommons.org/licenses/by/4.0/. The Creative Commons Public Domain Dedication waiver (http://creativeco mmons.org/publicdomain/zero/1.0/) applies to the data made available in this article, unless otherwise stated in a credit line to the data. 
Table 1 The active suPAR levels in plasma are associated correlated with high-sensitivity C-reaction protein (hs-CRP), neutrophil/leukocyte ratio, and lymphocyte counts

\begin{tabular}{|c|c|c|c|c|c|}
\hline Patient type & $\begin{array}{l}\text { Number } \\
\text { of samples }\end{array}$ & Active suPAR $(\mathrm{ng} / \mathrm{mL})$ & hs-CRP (mg/L) & $\begin{array}{l}\text { Neutrophil/leukocyte } \\
\text { ratio (\%) }\end{array}$ & Lymphocyte ( $\left.\times 10^{9} / \mathrm{L}\right)$ \\
\hline Moderate & 57 & $4.57 \pm 2.35$ & $3.01 \pm 3.67$ & $59.98 \pm 9.34$ & $1.62 \pm 0.60$ \\
\hline Severe & 30 & $5.97 \pm 2.31$ & $38.79 \pm 57.81$ & $64.60 \pm 11.23$ & $0.97 \pm 0.35$ \\
\hline Critical & 21 & $6.68 \pm 2.54$ & $135.39 \pm 93.88$ & $87.49 \pm 9.53$ & $0.66 \pm 0.37$ \\
\hline Asymptomatic & 9 & $8.08 \pm 4.81$ & $1.29 \pm 1.14$ & $65.78 \pm 9.30$ & $1.57 \pm 0.49$ \\
\hline
\end{tabular}
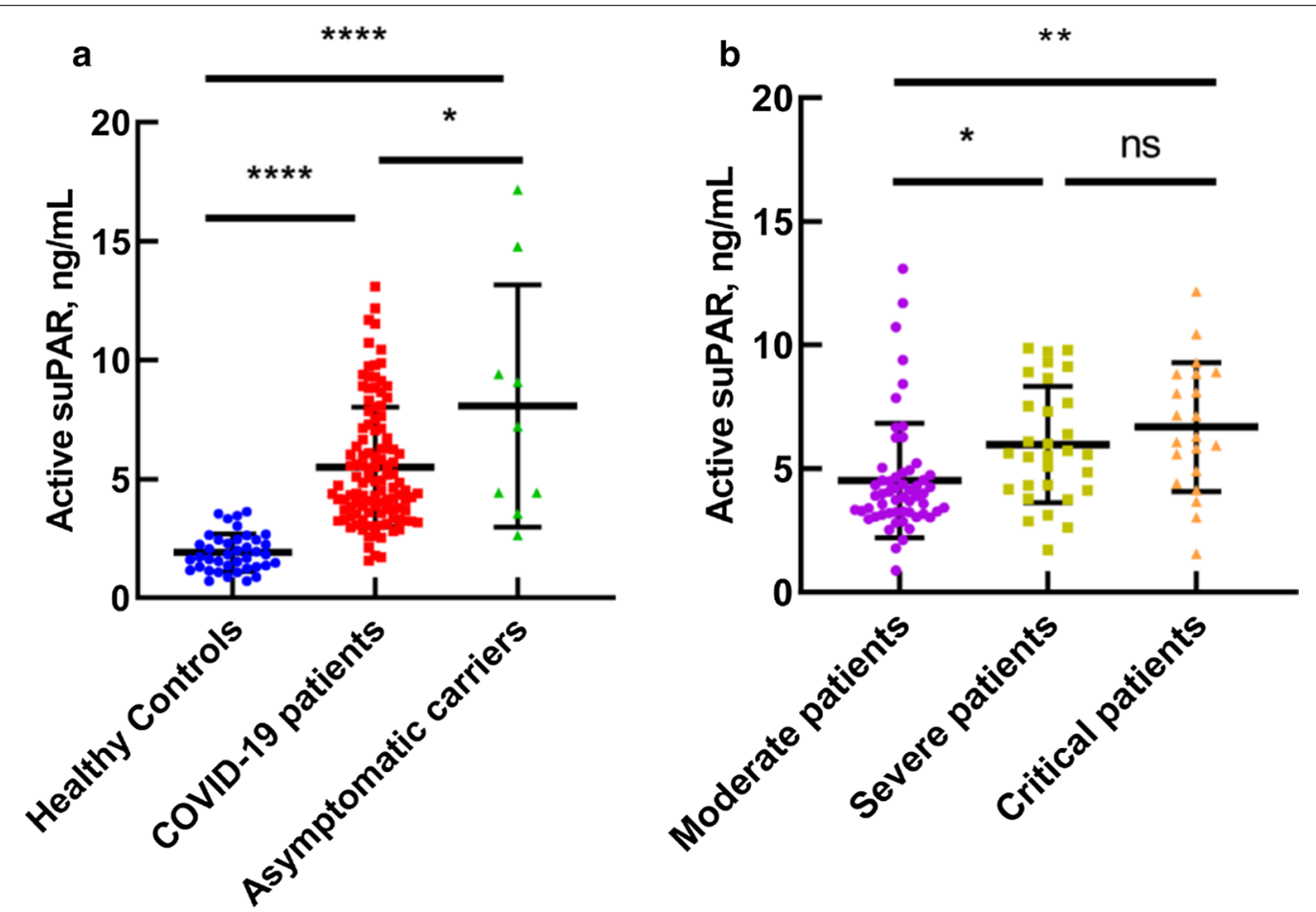

Fig. 1 Level of plasma active suPAR in different classifications. a Active suPAR level in COVID-19 patients and asymptomatic carriers, compared with active suPAR level in healthy controls. b Level of active suPAR between three different COVID-19 classifications including moderate, severe, and critical

\title{
Authors' response
}

\author{
Jesper Eugen-Olsen ${ }^{5}$, Salim Hayek ${ }^{6}$, Jochen Reiser ${ }^{7 *}$ and Evangelos J. Giamarellos-Bourboulis ${ }^{8,9^{*}}$ \\ *Correspondence: jochen_reiser@rush.edu; egiamarel@med.uoa.gr \\ ${ }^{5}$ Clinical Research Centre, Copenhagen University Hospital Hvidovre, Hvidovre, Denmark. \\ ${ }^{6}$ Department of Medicine, University of Michigan, Ann Arbor, MI 48103, USA. \\ ${ }^{7}$ Department of Medicine, Rush University Medical Center, Chicago, IL 60612, USA. \\ ${ }^{8}$ 4th Department of Internal Medicine, Medical School, National and Kapodistrian University of Athens, 11527 Athens, Greece. \\ ${ }^{9}$ 4th Department of Internal Medicine, ATTIKON University Hospital, 1 Rimini Street, 12462 Athens, Greece.
}

The urokinase plasminogen activator receptor (UPAR) is an immune cell expressed GPI-linked receptor that may be cleaved from the cell surface generating soluble uPAR (suPAR). There are three forms of the suPAR molecule, the full length 3-domain protein (DIDIIDIII), and the cleaved forms (DIIDIII) and DI; only DIDIIDIII can bind
uPA with high affinity generating soluble DIDIIDIII/uPA complexes [5]. Both the full length and DIIDIII molecules have been shown to carry independent prognostic value [6].

Huang et al. report that "active suPAR" increases with severity of COVID-19," but surprisingly find that the level 
is even higher among some of the 9 included asymptomatic carriers. As part of our "International consortium on inflammation in COVID-19," we have tested almost 1000 COVID-19 patients for suPAR. Among patients with no or mild symptoms of infection, we find average levels about $4 \mathrm{ng} / \mathrm{ml}$, much lower than those that are hospitalized [7]. To further confirm this finding, we measured suPAR in the plasma of 11 patients with very mild symptoms. All were adults who provided written informed consent with molecular identification of SARSCoV-2 by routine real-time PCR in the nasopharyngeal secretions sampled by a standard collection swab. Blood sampling was done within 15 min after swab collection; median suPAR was $2.0 \mathrm{ng} / \mathrm{ml}$ (range 1.70-5.21 ng/ml).

In the above studies of our group, but also in the vast majority of published studies so far, suPAR is measured by the suPARnostic ${ }^{\circledR}$ assays. These assays are using two monoclonal antibodies (developed into lateral flow quick tests, enzyme immunoassays, and turbidimetric assays on Roche, Abbott, and Siemens platforms) and are the only CE/IVD approved suPAR assays for clinical decision making on the market.

Why this difference between the suPARnostic ${ }^{\circledR}$ assays and the enzyme immunoassay is described by Huang et al.? Likely, because the suPARnostic ${ }^{\circledR}$ assays are developed based on prognostic value using combinations of antibodies on plasma from patients with known disease progression to identify antibodies that bind the suPAR molecules with the highest clinical value. On the contrary, the assay described by Haung et al. may capture only a subgroup of the prognostic relevant suPAR molecules.

In conclusion, our data using the suPARnostic ${ }^{\circledR}$ assays both in a large published cohort of patients $[1,7]$ and in a recent cohort of mild cases from Greece support that patients with asymptomatic or mild COVID-19 have lower levels of suPAR than severe cases.

\section{Abbreviations \\ COVID-19: Coronavirus disease 2019; ELISA: Enzyme-linked immunosorbent assay; hs-CRP: High-sensitivity C-reaction protein; SARS-CoV-2: Severe acute respiratory syndrome coronavirus 2; sUPAR: Soluble urokinase plasminogen activator receptor; uPA: Urokinase plasminogen activator.}

\section{Acknowledgement}

Not applicable.

\section{Authors' contributions}

All authors had full access to all of the data in the study and take responsibility for the integrity of the data. $\amalg$ has written the letter. The authors read and approved the final manuscript.

\section{Funding}

This study is financially supported by grants from the National Key R\&D Program of China (2017YFE0103200), Natural Science Foundation of China (82070142, 31670739, 22077016), Natural Science Foundation of Fujian Province (2018J01897 and 2018J01729), and Fuzhou Municipal Science and Technology Program (2020-XG-021).

\section{Availability of data and materials}

The dataset supporting the conclusion of this article is available from the corresponding author upon reasonable request.

\section{Ethics approval and consent to participate}

The study was approved by the Ethics Committee of the Fuzhou pulmonary hospital of Fujian. All subjects provided informed written consent documents in accordance with the Declaration of Helsinki before enrollment.

\section{Consent for publication}

Not applicable.

\section{Competing interests}

The authors declare that they have no competing interests.

\section{Author details}

1 Department of Clinical Laboratory, Fuzhou Pulmonary Hospital of Fujian, Fuzhou 350008, Fujian, China. ${ }^{2}$ College of Chemistry, Fuzhou University, Fuzhou 350116, Fujian, China. ${ }^{3}$ College of Biological Science and Engineering, Fuzhou University, Fuzhou 350116, Fujian, China. ${ }^{4}$ Fujian Key Laboratory of Marine Enzyme Engineering, Fuzhou University, Fuzhou, Fujian, China.

Received: 18 September 2020 Accepted: 7 October 2020

Published online: 29 December 2020

\section{References}

1. Rovina N, Akinosoglou K, Eugen-Olsen J, Hayek S, Reiser J, GiamarellosBourboulis EJ. Soluble urokinase plasminogen activator receptor (sUPAR) as an early predictor of severe respiratory failure in patients with COVID19 pneumonia. Crit Care. 2020;24(1):187.

2. Huai Q, Mazar AP, Kuo A, Parry GC, Shaw DE, Callahan J, Li Y, Yuan C, Bian $C$, Chen $L$, et al. Structure of human urokinase plasminogen activator in complex with its receptor. Science (New York, NY). 2006;311(5761):656-9.

3. D’Alonzo D, De Fenza M, Pavone V. COVID-19 and pneumonia: a role for the uPA/uPAR system. Drug Discov Today. 2020. https://doi.org/10.1016/j. drudis.2020.06.013.

4. Zhou X, Xu M, Huang H, Mazar A, labal Z, Yuan C, Huang M. An ELISA method detecting the active form of suPAR. Talanta. 2016;160:205-10.

5. Resnati M, Pallavicini I, Wang JM, Oppenheim J, Serhan CN, Romano M, Blasi F. The fibrinolytic receptor for urokinase activates the $\mathrm{G}$ proteincoupled chemotactic receptor FPRL1/LXA4R. Proc Natl Acad Sci USA. 2002;2002(99):1359-64.

6. Ostrowski SR, Piironen T, Høyer-Hansen G, Gerstoft J, Pedersen KB, Ullum $\mathrm{H}$. High plasma levels of intact and cleaved soluble urokinase receptor reflect immune activation and are independent predictors of mortality in HIV-1-infected patients. J Acquir Immune Defic Syndr. 2005;39:23-31.

7. Azam TU, Shadid HR, Blakely P, O'Hayer P, Berlin H, Pan M, et al. Soluble urokinase receptor (SuPAR) in COVID-19-related AKI. J Am Soc Nephrol. 2020. https://doi.org/10.1681/ASN.2020060829.

\section{Publisher's Note}

Springer Nature remains neutral with regard to jurisdictional claims in published maps and institutional affiliations. 